Çukurova Üniversitesi Mühendislik Mimarlık Fakültesi Dergisi, 33(3), ss. 145-152, Eylül 2018

Çukurova University Journal of the Faculty of Engineering and Architecture, 33(3), pp. 145-152, September 2018

\title{
Fononik Kristalerde Ses Dalgasının Dispersiyon Özellikleri: Sonlu Elemanlar Analizi
}

\author{
Zafer ÖZER ${ }^{* 1}$ \\ ${ }^{1}$ Mersin Üniversitesi, Mersin Meslek Yüksekokulu, Elektronik ve Otomasyon Bölümü, Mersin
}

Geliş tarihi: 06.07.2018 Kabul tarihi: 15.10 .2018

$\ddot{\mathbf{O z}}$

$\mathrm{Bu}$ çalışmada farklı tasarımlardaki fononik kristallerin dispersiyon özellikleri deneysel olarak FFT algoritması ve nümerik olarak sonlu elemanlar yöntemi kullanılarak araştırılmıştır. Periyodik olarak yerleştirilmiş kompozit silindirlerden oluşan kare örgü ve yarı-periyodik (Fibonacci dizilimi) yapıdaki iki boyutlu fononik kristal de, birinci Brillouin bölgesinde dalga vektörüne $(k)$ karşılık frekanslar elde edilerek $\mathrm{M}-\Gamma-\mathrm{X}-\mathrm{M}$ yolu boyunca fononik bant yapıları çizdirildi. Periyodik fononik kristal tasarımlarından dolu kompozit silindirlerden oluşan yapıda $4 \mathrm{kHz}-7 \mathrm{kHz}$ aralığında $\Gamma-\mathrm{X}$ yönünde kısmi bant, nümerik olarak incelenen c-şekilli fononik kristalde $2 \mathrm{kHz}-3 \mathrm{kHz}$ aralığında tam bant, Fibonacci dizilimindeki fononik kristalde ise $3 \mathrm{kHz}-4 \mathrm{kHz}$ ve $3,5 \mathrm{kHz}-6,7 \mathrm{kHz}$ aralıklarına $\Gamma-X$ yönünde kısmi bantlar gözlendi. Sonuçların geçerliliğini test etmek için sonlu yapıda iletim kayıpları nümerik olarak hesaplandı ve deneysel olarak ölçüldü. Fononik bant yapısı ile elde edilen iletim kayıpları karşılaştırıldığında sonuçların uyumlu oldukları gözlendi.

Anahtar Kelimeler: Fononik kristal, Dispersiyon özellikleri, Sonlu elemanlar metodu

\section{Dispersion Features of the Sound Waves in Phononic Crystals: Finite Element Analysis}

\begin{abstract}
In this study, dispersion properties of phononic crystals in different design were investigated experimentally by using FFT algorithm and numerically by using finite elements method. In the first Brillouin zone, frequencies corresponding to the wave vector $(k)$ obtained and phononic band diagram were plotted along the $\mathrm{M}-\Gamma-\mathrm{X}-\mathrm{M}$ path for the two dimensional phononic crystals which were periodically placed composite cylinders with square lattice and quasi-periodic (Fibonacci sequence). In the periodic phononic crystal designs, partial band in $\Gamma-\mathrm{X}$ direction between $4 \mathrm{kHz}-7 \mathrm{kHz}$ in the structure consist of full composite cylinders, full band between $2 \mathrm{kHz}-3 \mathrm{kHz}$ range in the numerically studied C-shaped phononic crystal, and partial bands in $\Gamma-\mathrm{X}$ direction between in the $3 \mathrm{kHz}-4 \mathrm{kHz}$ and $3.5 \mathrm{kHz}-6.7 \mathrm{kHz}$ ranges in Fibonacci phononic crystal were observed. In order to compare validity of the results, in the finite structure the transmission losses were calculated numerically and measured experimentally. When the phononic band structure compare with the obtained transmission losses, it was observed that the results were compatible.
\end{abstract}

Keywords: Phononic crystal, Dispersion features, Finite element method

*Sorumlu yazar (Corresponding author): Zafer ÖZER, zaferozer@mersin.edu.tr 


\section{GíRiș}

Fononik kristaller (FnK), fotonik kristallerin akustik/elastik dalga benzeri olup homojen bir malzeme içerisine bulunan çubuklardan oluşan 1 boyutlu (1D), iki boyutlu (2D) veya üç boyutlu (3D) periyodik yapılardır. FnK'ler, kristal içerisinde belirli aralıklardaki akustik frekanslardaki dalgaların ilerlemesinin yasaklandığı "akustik bant boşluğu” denen yasak bantlara sahiptir. Akustik/ elastik dalgaların yayılması, çubukların ses hızı, yoğunluğu/elastik özellikleri, şekli ve düzeni (kare, üçgen, bal peteği örgü vs.), yapıdaki yayılmasını önemli ölçüde etkiler. Değişik malzeme, örgü veya çubukların seçimi ile fononik kristalin bant yapısı değiştirilebilir. Fononik kristallerin dispersiyon eğrileri elde edildiğinde, belirli frekansların ilerlemesinin yasaklandığı tam bantlar oluştuğu gibi, sadece belirli yönlerdeki ilerlemesinin yasak olduğu kısmi bantlara sahip olabilir [1-4].

Bant boşluğun oluşması için genel mekanizma, fononik kristaldeki çubuklara çarparak saçılan akustik/elastik dalgaların, yıkıcı girişimlerine dayanır bu nedenle malzemelerin yoğunluk-ses hızı/elastik özellikleri arasında farkın yüksek olmasını gerektirir. Bragg saçılmasında ilk bant genellikle ses hızı "c" ve örgü sabiti "a" c/a frekansında gerçekleşir [3]. Bu durumda alt dalga boyu büyüklüğünde düşük frekanslı bir bant boşluğu elde etmek zordur. Ancak yerel rezonanslı çubukların kullanılması durumunda örgü parametresinin iki kat altındaki frekanslarda fononik bantlar oluşabilir. Doğal materyallerde bulunmayan akustik özelliklere sahip periyodik yapılar akustik metamateryaller olarak isimlendirilir. Helmholtz resonatör, Mie-tip rezonans vs. yapılarla lokal resonanslı akustik metamateryaller elde edilebilir. $\mathrm{Bu}$ yapıların akustik perdeleme, akustik lens görüntüleme gibi geniş uygulama alanları vardır [5].

Periyodik, yarı-periyodik veya düzensiz, FnK'lerde akustik/elastik dalgaların işlenmesi ve kontrolü ile gerçekleştirilen, sinyal işleme, dalga kılavuzu, nano boyutta sensörler, entegre akusto-optik, akustik materyaller, radyo frekans iletişimi, tıbbi ultrason alanında akustik görüntüleme gibi pek çok uygulamalar vardır [1,6-17]. Deprem etkilerini azaltabilmek için sismik metamateryaller ve piezoelektrik malzemeler kullanılarak yüzey akustik dalgaları ile çalışan sensörlerle ile ilgili çalışmalar yapılmıştır $[18,19]$.

Bunların dişında FnK savunma sanayi (denizaltıların motor seslerinin absorbe edilmesi), önemli yapı ve sistemlerin depremlerde korunması vs. alanlarda da kullanma kapasitesine sahiptirler $[19,20]$. FnK özelliklerinin deneysel ve teorik olarak incelenmesi farklı yöntemlerle yapılmaktadır.

Sonlu elemanlar yöntemi farklı mühendislik alanlarında kullanılan yaygın bir analiz yöntemi olup, tasarım aşamasında önemli ölçüde zaman ve para tasarrufu sağlar. Bu çalışmada, SEM ile elde edilen 2D FnK bant yapısı, deneysel olarak elde edilen verilerle karşılaştırılarak yöntemin geçerliliğini test edildikten sonra farklı 2D FnK tasarımlarının bant yapıları sonlu elemanlar metodu (SEM) ile incelenmiştir.

\section{TEORI}

FnK'deki fononik bant boşlukları, katı hal fiziğindeki elektronik bant yapılarına benzemektedir. Dalga gibi davranan elektronun dalga boyu, Bragg şartlarını sağladığında kırınım gerçekleşir [1].

Genişlikleri $a / 2$ olan iki farklı malzemeden meydana gelen periyodik yapıda, ses hızının yüksek olduğu malzeme ile ses hızının düşük olduğu malzemelerde zarf fonksiyonunun maksimum noktaları bulunabilir ve $k$ ya bağlı bağlı frekans için aynı dalga sayısına karşılık iki frekans oluşabilir $\{\omega=\omega(k)\}$. Bu durumda dalga hızları arasındaki farkın büyüklüğü ile doğru orantılı genişlikte fononik bant boşluğu meydana gelir. Akışkan-katı fononik kristallerdeki çubukların rijit yapıda olmasından dolayı, mekanik dalga daha çok akışkanda ilerler [21]. $Z$ yönünde uzanan silindirlerden oluşan FnK' de mekanik özellikler $x y$ düzleminde sonsuza uzandığından mekanik 
özellikler $z$ yönünden bağımsız olarak $x y$ yönünde değişir. Katı-akışkan malzemelerin periyodik diziliminden oluşan FnK'da akustik Bloch dalgasının hareketi, denklem (1) deki akustik dalga denklemi ile ifade edilir.

$$
\nabla\left(\frac{1}{\rho} \nabla \mathrm{p}\right)=-\frac{1}{\rho c^{2}}(\omega(\tilde{\mathrm{k}}))^{2} \cdot \mathrm{p}
$$

Bu denklemde $\rho=\rho(\tilde{r})$ yoğunluk, $\quad c=c(\tilde{r})$ akustik dalganın fononik kristaldeki boyuna hızı ve $p=p_{k}(\tilde{r})$ fononik kristalde $p_{k}(\tilde{r}, t)$ basincina sahip dalga vektörlü akustik Bloch dalgasının konuma bağlı durumunu ifade eder. İki boyutlu fononik kristalde dalga denklem 2'deki hale gelir.

$$
\frac{\partial}{\partial x}\left(\frac{1}{\rho} \frac{\partial p}{\partial x}\right)+\frac{\partial}{\partial y}\left(\frac{1}{\rho} \frac{\partial p}{\partial y}\right)=-\frac{1}{\rho c^{2}}(\omega(\tilde{k}))^{2} \cdot p
$$

Burada $\rho=\rho(x, y)$ ve $c=c(x, y) 2 \mathrm{D}$ fononik kristalin mekanik özellikleri ve $p$ uzaysal basınç $p_{k}(x, y)$ dir. Periyodik yapının fononik bant boşluğunun bulunduğu aralıktaki bir frekansa sahip mekanik dalga, periyodik yapıda ilerleyemediği için tamamen geri yansitılır. Eğer mekanik dalga fononik kristal içerisinde oluşmuşsa, fononik kristal tarafindan hapsedilerek yayılması engellenir.

\section{MATERYAL VE METOT}

Deneysel çalışmada literatürde çoğunlukla çalışılan yapı olan, hava içerisinde $x y$ düzleminde periyodik olarak dizilmiş, $z$ yönünde sonsuz uzunlukta $7 \times 10$ kompozit silindirlerden oluşan 2D fononik kristal kullanılmıştır. SEM'le iletim kaybı hesaplamalarında Şekil 1'deki kesik çizgi ile gösterilen birim hücre kullanılmıştır. Birim hücrenin sağına ve soluna "Perfectly Matched Layer" sınır koşulları, alt ve üst kenarlarına "Symmetry Boundary Condition" sınır koşulları uygulanmıştır. Akustik dalganın fononik kristaldeki dispersiyon özelliklerini analiz etmek için Şekil 2'de görülen periyodik iki farklı yapı tasarlanmıştır. Bu tasarımlar sırayla dolu silindir ve c-şekilli çubuklar olup parametreler şu şekildedir; örgü sabiti $a=30 \mathrm{~mm}, r l=10 \mathrm{~mm}, r 2=9 \mathrm{~mm}-5 \mathrm{~mm}$, $w=1 \mathrm{~mm}-4 \mathrm{~mm}$. Başl1k 3.1'de düşük frekanslarda ses izolasyonu amaçlı olarak kullanılabilecek yerel rezonansa sahip c-şekilli tasarımında, $w$ genişliği $1 \mathrm{~mm}-4 \mathrm{~mm}$ arasında, $r 1-r 2$ cidar kalınlığ $1 \mathrm{~mm}-5 \mathrm{~mm}$ arasında değiştirilerek bant yapısına etkisi, başlık 3.2 ise basınç alanı ile bant yapısı arasındaki uyum incelenmiştir. Analizde kullanılan malzemelere ait parametreler Çizelge 1'deki gibi olup, iletim kaybı [22] fononik kristalde dalganın ilerleme yönüne göre periyodik yapının önünde ve arkasında tanımlanan A ve B noktaları ile takip edilmiştir (Şekil 1).

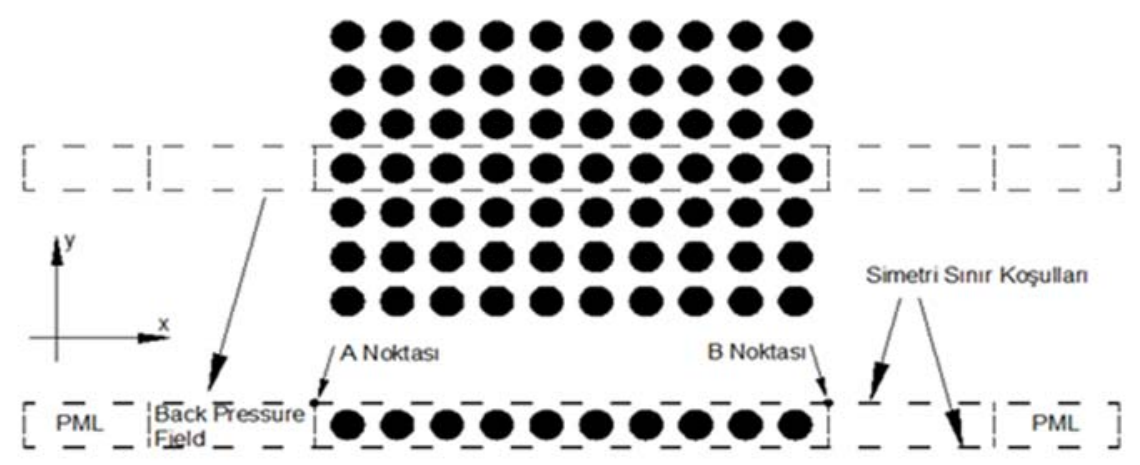

Şekil 1. Sonlu yapıdaki fononik kristal ve sınır koşulları

SEM ile elde edilen sonuçların geçerliliğini test etmek için Şekil 2.a'da görülen dolu silindirlerden oluşan FnK deney düzeneği olarak kurulmuş ve ölçümler yapılarak sonuçlar karşılaştırılmıştır. Örgü sabitinden bağımsız olan Şekil 2.b'deki yerel rezonanslı FnK tasarlanarak SEM ile dispersiyon özelliklerini analiz edilmiştir. 


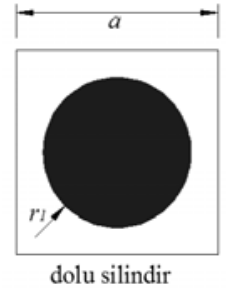

a

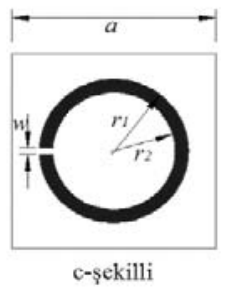

Şekil 2. Birim hücre ve silindir tasarımları

Çizelge 1. Analizde kullanılan malzemelerin özellikleri

\begin{tabular}{|l|c|c|}
\hline & Kompozit Malzeme & Hava \\
\hline Ses hızı (m/s) & 1420 & 343 \\
\hline Yoğunluk (kg/m $\left.\mathbf{m}^{\mathbf{3}}\right)$ & 690 & 1,25 \\
\hline
\end{tabular}

Deneysel olarak, hava içerisindeki 10x7 kare örgü diziliminde (Şekil 1) örgü sabiti $a=30 \mathrm{~mm}$, yarıçapı

$r=10 \mathrm{~mm}$, uzunluğu $L=300 \mathrm{~mm}$ olan kompozit malzemeden yapılmış silindirlerden oluşan fononik kristalin iletim kayıpları elde edilmiştir. Bu amaçla yankısız ortamda fononik kristalden $1 \mathrm{~m}$ uzağa yerleştirilen hoparlörle, $100 \mathrm{~Hz}-16000 \mathrm{~Hz}$ aralığında sinüsoidal ses sinyali gönderilmiştir.

Standart FFT algoritması kullanılarak, FnK nin arkasına yerleştirilen audio-technica marka mikrofonun ile M-Audio [23] marka harici ses kartı üzerinden bilgisayara kaydedilen ses sinyalinin Fourier dönüşümü elde edilmiştir (Şekil 3b).

FnK'nın SEM ile elde edilen bant yapısı ile deneysel yöntemle elde edilen ses basınç seviyesi (dB) karşılaştırılarak yöntemin geçerliliği test edilmiştir. Şekil 3'deki gölgelendirilmiş alanlar bant yapılarını göstermektedir.

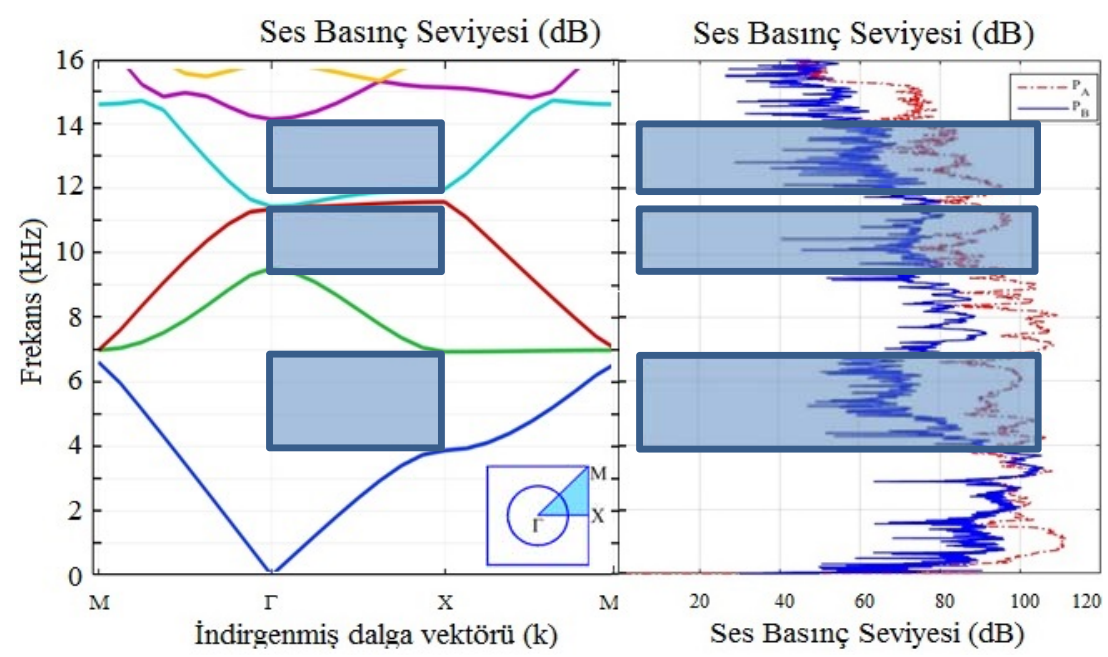

a)

b)

Şekil 3. a) Kare örgü bant yapısı b) deneysel olarak elde edilen ses basınç seviyesi [Sound Pressure Level $(\mathrm{dB})]$ değeri

\subsection{C-şekilli Tasarımda $w$ Genişliğinin ve Cidar (r1-r2) Kalınlığının Bant Yapısına Etkisi}

C-şekilli rezonatör, akustik olarak sabit bir hacimde hava içeren Helmholtz rezonatörüne benzer şekilde hareket eder, rezonatörlerdeki $w$ aralığının artması geniş bant aralıkları oluşumuna neden olur.

Akustik basınç değişimi açıklıktaki havayla etkileşime girdiğinde içerdeki havanın basıncı artar.
C-şekilli yapının içindeki havanın ataletinden dolayı boşlukta düşük basınç oluşur ve bu da havanın içeri geri çekilmesine neden olur. Hava daha sonra, rezonatörün boşluğunun ve açıklığın karakteristik boyutlarına bağlı olan rezonans $\omega_{0}$ frekansinda titremeye devam eder, ancak bu frekans şekil ve malzemeden bağımsızdır.

C-şekilli rezonans yapıların rezonans $\omega_{0}$ frekansı, Helmholtz rezonatörleri için kullanılan denkleme 
göre ayarlanabilir. Sabit bir yarık genişliği ve duvar kalınlığ olarak azalır [1].
Şekil 4'de $a=30 \mathrm{~mm}, r l=10 \mathrm{~mm}, r 2=9 \mathrm{~mm}$ ve $w=1$ mm olan c-şekilli yapının bant yapısı ve iletim kayıpları görülmektedir. Gölgeli alanda görüldüğü gibi yerel olarak $2 \mathrm{kHz}$ civarında tam bant oluşmuştur.

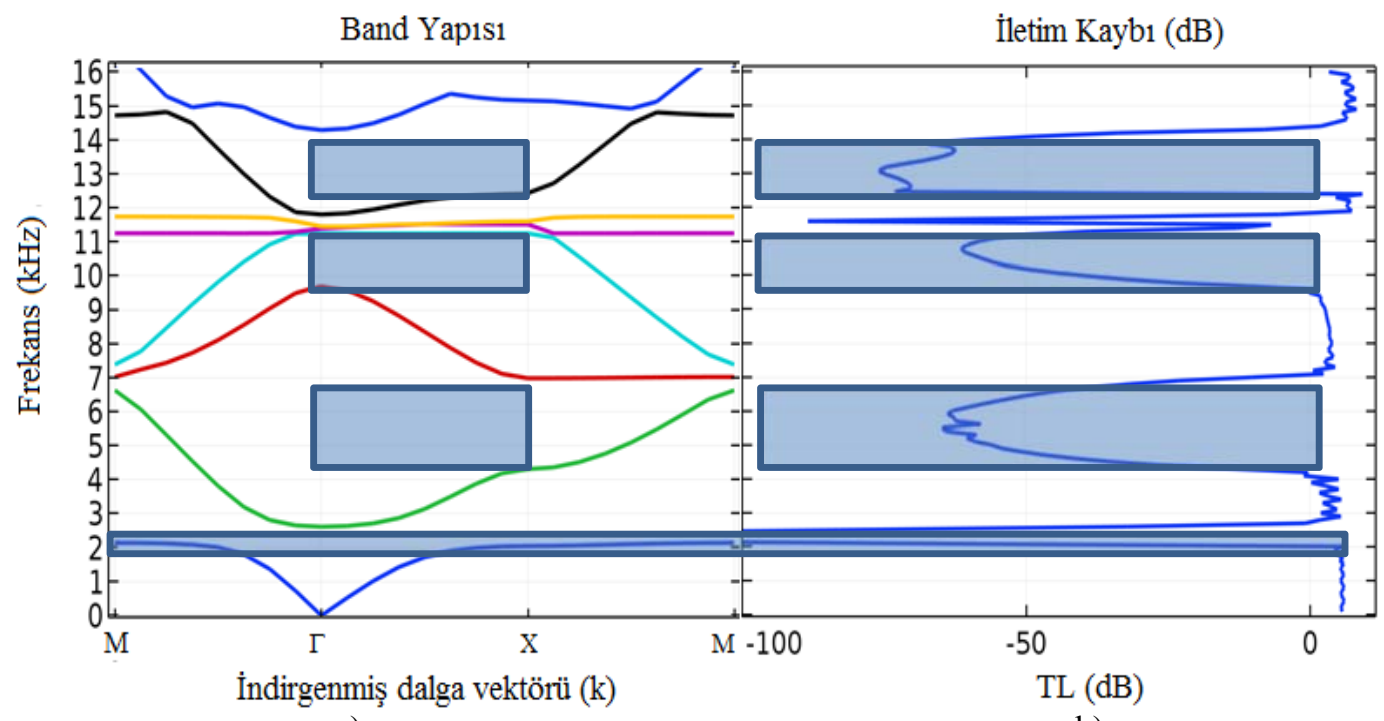

a)

b)

Şekil 4. a) c-şekilli tasarımın bant yapısı b) SEM analizi ile elde edilen iletim kaybı değeri

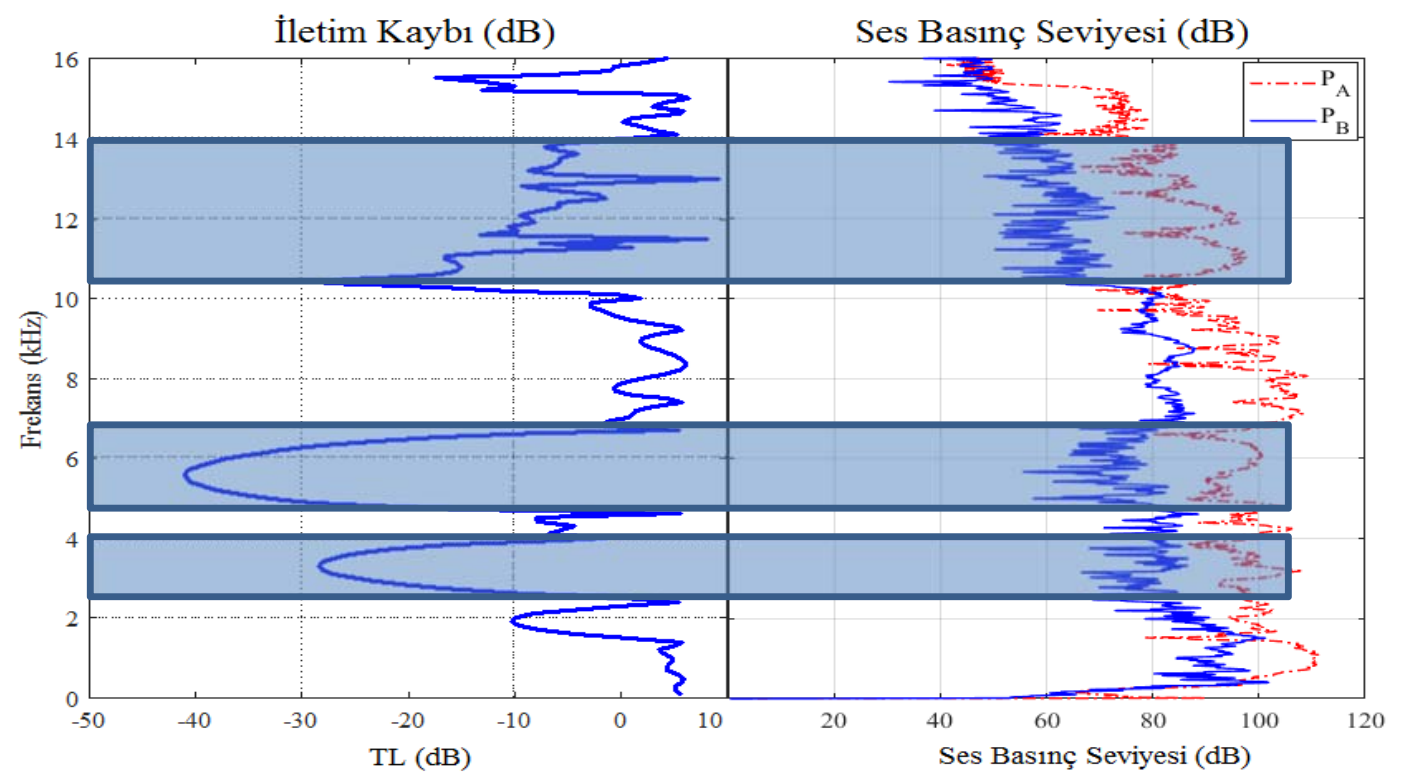

a)

b)

Şekil 5. Fibonacci modeline göre yarı-periyodik FnK için a) SEM analizi ile elde edilen iletim kaybı değeri b) deneysel olarak elde edilen ses basınç seviyesi Level (dB) değeri 
SEM kullanılarak, c-şekilli tasarımda $w$ genișliği ve cidar kalınlığının ( $r 1-r 2)$ bant boşluğuna etkisi araştırılmıştır. Şekil 3'de görülen $w$ aralığına bağlı olarak bant boşluğunun genişliği ve merkez frekans Çizelge 2'de görüldüğü gibi doğru orantılı olarak artmıştır. Buna karşılık Çizelge 3'de görüldüğü gibi cidar kalınlığı artırıldığında merkez frekans yükselirken, bant genişliği ise azalmıştır.

Çizelge 2. $w$ açıklığ 1 ile bant ilişkisi

\begin{tabular}{|c|c|c|}
\hline $\boldsymbol{w}(\mathbf{m m})$ & $\begin{array}{c}\text { Merkez frekans } \\
\mathbf{( H z )}\end{array}$ & $\begin{array}{c}\text { Bant genişliği } \\
\mathbf{( H z )}\end{array}$ \\
\hline 1 & 2044,98 & 217,47 \\
\hline 2 & 2391,31 & 26975 \\
\hline 3 & 2620,45 & 308,24 \\
\hline 4 & 2803,51 & 340,99 \\
\hline
\end{tabular}

Çizelge 3. Cidar kalınlığı ile bant ilişkisi

\begin{tabular}{|c|c|c|}
\hline $\boldsymbol{r}_{\mathbf{1}}-\boldsymbol{r}_{2}(\mathbf{m m})$ & $\begin{array}{c}\text { Merkez } \\
\text { frekans (Hz) }\end{array}$ & $\begin{array}{c}\text { Bant genişliği } \\
\mathbf{( H z )}\end{array}$ \\
\hline 2 & 2078,78 & 174,33 \\
\hline 3 & 2032,56 & 141,88 \\
\hline 4 & 2144,78 & 116,97 \\
\hline 5 & 2355,69 & 97,40 \\
\hline
\end{tabular}

\subsection{Fononik Kristal Basınç Alanı ile Bant Aralığı İlişkisi}

Örgü sabiti $a=30 \mathrm{~mm}$ ve silindir yarıçapı $r=10 \mathrm{~mm}$ olan FnK'nin SEM kullanılarak elde edilen bant yapısı (Şekil 3a) ve deneysel olarak elde edilen akustik basınç seviyesi (Şekil 3.b) görülmektedir. SEM ile elde edilen bant aralıkları ve deneysel olarak elde edilen akustik basınç seviyesi Sound Pressure Level (dB) ile karşılaştırmıştır. Buna göre yansıyan dalganın artış gösterdiği $4000 \mathrm{~Hz}-6000 \mathrm{~Hz}$ arasında Bragg bant aralığ oluşmuştur, sonuçlar birbiri ile uyumludur.

Şekil 6'da görüldüğü gibi fononik kristalin gerisinde bulunan B noktasında, en yüksek akustik basınç azalmasının olduğu $5500 \mathrm{~Hz}$ de, akustik basınç $70 \mathrm{~dB}$ kadar azalmış olup dalganın fononik kristal içerisinde ilerleyemediği görülmektedir.

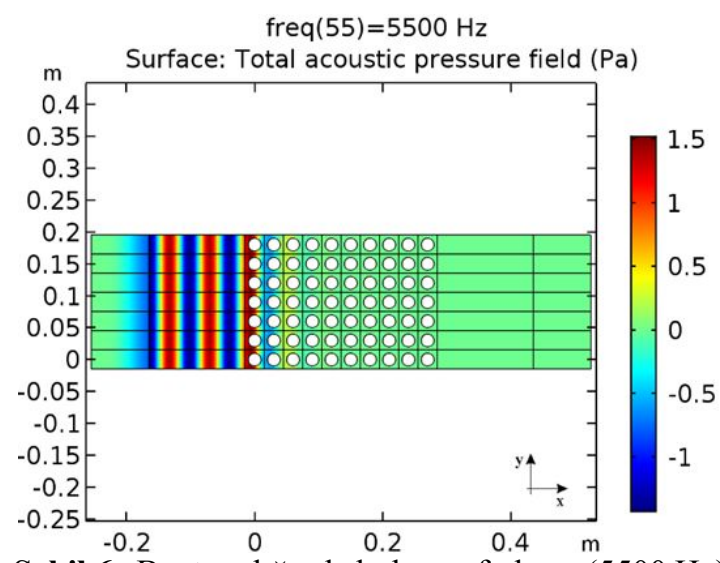

Şekil 6. Bant aralığında bulunan frekans $(5500 \mathrm{~Hz})$ için elde edilen akustik basınç $(\mathrm{Pa})$

Periyodik olmayan (yarı-periyodik) seri açılımının bant yapısına etkisini incelemek üzere Fibonacci dizilimi şeklinde tasarlanan FnK'nin bant yapısı deneysel olarak ve SEM ile elde edildi. Fibonacci dizisi $F_{j+1}=F_{j-1}, F_{j}, j \geq 1$ şeklinde tanımlanmakta olup $F_{j} j$. dereceden Fibonacci dizilimidir. Fibonacci dizilimini şeklinde FnK tasarımı elde etmek için kompozit silindirler A, hava B olarak tanımlandığında $F_{0}=\mathrm{A}, \quad F_{l}=\mathrm{B}$ için j iterasyon sonucunda elde edilen ilk 4 generasyon Çizelge 4'deki gibi olur.

Şekil 7'de Fibonacci serisine göre 4. generasyon FnK tasarımı görülmektedir, bu yapıya Şekil 2'deki sınır şartları uygulandığında elde edilen SEM çözümü ve deneysel ölçüm sonucu Şekil 5'de görülmektedir. Şekil 3'de aynı örgü sabitine sahip periyodik yapıdaki FnK'da ilk bant 4000-6000 Hz aralığında oluşurken, Fibonacci serisi dizilimindeki FnK'da ilk bant 2000-4000 Hz aralığındaki daha düşük frekans aralığında oluşmuştur.

Çizelge 4. Fibonacci serisi

\begin{tabular}{|c|c|c|c|}
\hline $\begin{array}{c}\text { Fibonacci } \\
\text { dizilimi }\end{array}$ & $\boldsymbol{F}_{\boldsymbol{j}+\mathbf{1}}=\boldsymbol{F}_{\boldsymbol{j}-\mathbf{1}}, \boldsymbol{F}_{\boldsymbol{j}}$ & $\begin{array}{c}\text { Fibonacci } \\
\text { sayısı }\end{array}$ & $\begin{array}{c}\text { Generasyon } \\
\text { numarası }\end{array}$ \\
\hline$F_{0}$ & $\mathrm{~A}$ & 1 & 0 \\
\hline$F_{1}$ & $\mathrm{~B}$ & 1 & 1 \\
\hline$F_{2}$ & $\mathrm{AB}$ & 2 & 2 \\
\hline$F_{3}$ & $\mathrm{ABA}$ & 3 & 3 \\
\hline$F_{4}$ & $\mathrm{ABAAB}$ & 5 & 4 \\
\hline
\end{tabular}




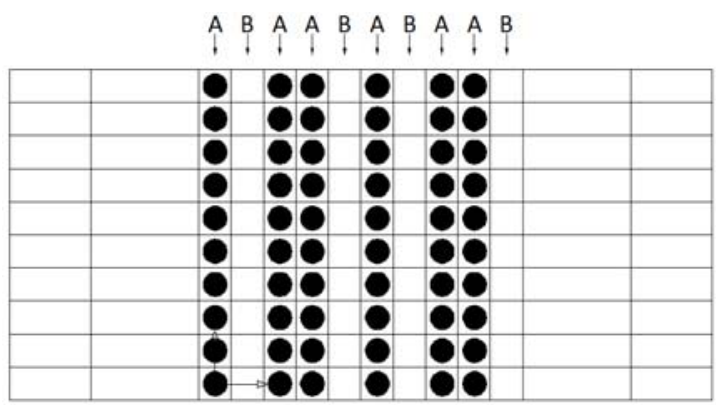

Şekil 7. 4. generasyon Fibonacci serisi şeklinde dizilmiş FnK tasarımı

\section{BULGULAR VE TARTIŞMA}

$\mathrm{Bu}$ çalışmada dolu silindir ve lokal rezonanslı cşekilli 2D fononik kristalde, ses dalgasının dispersiyon özellikleri SEM ile incelenmiştir. 2D fononik kristal hava içerisinde periyodik olarak dizilen silindirlerden olușmaktadır. Fononik kristalin bant yapısı ve iletim kayıpları SEM analizi ile akustik basınç seviyesi ise FFT algoritması ile elde edilmiş olup elde edilen sonuçlar uyumludur.

Simulasyonu yapılan c-şekilli rezonatör, düşük frekansta ses seviyesinde zayıflama sağlayan geniş bant yapısına sahiptir. C-şekilli rezonatör kullanıldığında bu geometri "kara cisim black body" modelini çağrıştırıyor ve bu geometri için parametrelerin değişimi bizlere farklı frekans aralıklarında yasak bantların oluşumunu temin edebilecektir. Bu nedenle başlık 3.1'de c-şekilli yapıda bant yapısı parametrik olarak incelenmiştir.

Aynı zamanda rezonatör tasarımında kullanılan parametrelerle (yoğunluk ve ses hızı), örgü yapısı değiştirilerek akustik ses seviyesinin düşürüleceği farklı frekans aralığına sahip yapılar geliştirilebilir.

Başlık 3.2'de bant aralığ ile bu aralıkta yer alan frekansa sahip ses dalgasının basınç seviyesindeki azalma karşılaştırılarak aralarında uyum incelenmiştir. Bant yapısını elde ettiğimiz FnK'da belirli frekanslarda, dalganın yapı içerisinde ilerleyemediği yasak bantlar oluşmuştur. Periyodik veya yar1-periyodik (Fibonacci) FnK'larda SEM ile elde edilen bant yapısında görülen frekans aralığında, ses basınç seviyesinde azalma olup olmadığını incelemek üzere Şekil 1 (periyodik) ve
Şekil 7'deki (periyodik olmayan) sonlu yap1 oluşturularak ses basınç seviyesi elde edilmiştir. Şekil 3.a'da 4000-6000 Hz aralığında kısmi bantta yer alan $5500 \mathrm{~Hz}$ frekanslı ses dalgasının FnK'da ki ses basınç seviyesine baktığımızda Şekil 6'da görüldüğü gibi dalganın periyodik yapıda ilerleyemediği görülmektedir.

Çalışma şartlarımızın kısıtlamalarına rağmen yarıperiyodik olarak Fibonacci dizilimi şeklindeki tasarladığımız FnK'nin SEM ve deneysel ölçüm sonuçları göstermiştir ki (Şekil 5), yarı-periyodik FnK'de de örgü sabitinden bağımsız düşük frekanslardan başlayan fononik bant boşlukları elde edilebilir. Bu çalışmadaki bulgular göstermiştir ki, akustik FnK tasarımlarının geliştirilmesi ile akustik filtre ve akustik yalıtım konularında yeni cihazlar üretilebilir. Önerilen yapı kullanılarak, alt frekans ve üst frekanslarda bant yapısına sahip sismik ve ultrasonik yapılar üretilebilir.

\section{KAYNAKLAR}

1. Elford, D.P., 2010. Band Gap Formation in Acoustically Resonant Phononic Crystals, Doctoral Thesis, Loughborough University Institutional Repository, Loughborough.

2. Liu, X.J., Fan, Y.H., 2013. Band Structure Characteristics of T-square Fractal Phononic Crystals, Chin. Phys. B, 22, 036101.

3. Khelif, A., Abidi, A., 2016. Phononic Crystal Fundamental and Applications, Springer, p.23-24, New York.

4. Korozlu, N., 2017. Fononik Kristal Kaplama ile Gösteri Salonlarında Akustik Yalıtımın Sayısal İncelenmesi, Dokuz Eylül ÜniversitesiMühendislik Fakültesi, Fen ve Mühendislik Dergisi, 19, 56.

5. Hongqing, D., Baizhan, X., Dejie, Y., 2017. Dirac Cones in Two-dimensional Acoustic Metamaterials, Journal of Applied Physics, 122, 065103.

6. Maetani, N., Kurose, T., Tsuruta, K., 2010. Numerical Simulation of Acoustic Waves in Two-Dimesional Phononic Crystal: Negative Refraction, Memoirs of Faculty of Engineering, -Okayama University, 44, 7-12. 
7. Su, M.F., Olsson R.H., Leseman, Z.C., El-Kady, I., 2010. Realization of a Phononic Crystal Operating at Gigahertz Frequencies, Applied Physics Letters, 96, 053111.

8. Kurose, T., Tsuruta, K., Totsuji, C., Totsuji, H., 2009. Negative Refraction of Acoustic Waves in a Two-Dimensional Phononic Crystal via FDTD Simulation, Materials Transactions, 50, 1004-1007.

9. Alaie, S., Su, M.F., Goettler, D.F., El-Kady, I., Leseman, Z., 2013. Effects of Flexural and Extensional Excitation Modes on the Transmission Spectrum of Phononic Crystals Operating at Gigahertz Frequencies, J. Appl. Phys., 113, 103513.

10. Xue-Feng, Z., Sheng-Chun, L., Tao, X., T., TieHai, W., Jian-Chun, C., 2010. Investigation of a Silicon-based One-dimensional Phononic Crystal Plate Via the Super-cell Plane Wave Expansion Method, Chin. Phys. B, 19, 044301.

11. Meidani, M., Kim, E., Li, F., Yang, J., Ngo, D., 2015. Tunable Evolutions of Wave Modes and Band Gaps in Quasi-1D Cylindrical Phononic Crystals, Journal of Sound and Vibration, 334, 270-281.

12. Lucklum, R., Zubtsov, M., Oseev, A., Schmidt, M.P., Hirsch, S., Hagemann, F., 2013. Phononic Crystals and Applications, doi 10.5162/sensor2013/A3.1.

13. Pachiu, C., Ion, M.J., Izbicki, L., Moagar, V., 2011. Congrès Français de Mécanique, Besançon, 29 août au 2 Septembre 2011.

14. Chiyan, L., Johnson, S.G., Joannopoulos, J.D., 2002. All-angle Negative Refraction Without Negative Effective Index, Phys. Rev. B, 65, 201104-201107.

15. Pashchenko, V., Yankin, S., 2013. Surface Acoustic Wave Ferroelectric Phononic Crystal Based on Electric Field Induced Periodic Domains, COMSOL Conference 2013.

16. Olsson, R.H., El-Kady, I., 2008. Microfabricated Phononic Crystal Devices and Applications, Measurement Science and Technology, 20, 1.

17. Gkantzounis, G., Florescu, M., 2017. Freeform Phononic Waveguides, Crystals, 12, 353.

18. Chung, G., Phan, D.T., 2010. Finite Element Modeling of Surface Acoustic Waves in
Piezoelectric Thin Films, Journal of the Korean Physical Society, 57, 446-450.

19. Brûlé, S., Javelaud, E.H., Enoch, S., Guenneau S., 2014. Experiments on Seismic Metamaterials, Physical Reviewletters, 112, 133901.

20. Qian, D., Shi, Z., 2016. Bandgap Properties in Locally Resonant Phononic Crystal Double Panel Structures with Periodically Attached Spring-mass Resonators, Physics Letters A, 380, 41.

21. Oltulu, O., Simsek, Ş., Mamedov, A.M., Ozbay, E., 2016. Phononic Band Gap and Wave Propagation on Polyvinylidene fluoride Based Acoustic Metamaterials, Cogent Physics, 2: 1169570.

22. Wang, Z., 2011. Development of Acoustic Models for High Frequency Resonators for Turbocharged Ic-Engines, Master Thesis in Sound \& Vibration Stockholm, Sweden.

23. http://www.audiotechnica.com/cms/wired_mics/8ba9f72f1fc02b c5/index.html (18.05.2018) 